\title{
Wine Consumption in the Mediterranean Diet: Old Concepts in a New Sight
}

\author{
Caterina Carollo*, Gregorio Caimi \\ Department of Internal and Specialistic Medicine, University of Palermo, Palermo, Italy. \\ Email: caterina.carollo@unipa.it
}

Received October 21 $1^{\text {st }}, 2012$; revised November $21^{\text {st }}, 2012$; accepted November $28^{\text {th }}, 2012$

\begin{abstract}
The term "Mediterranean diet" is widely employed to indicate the typical diet of the Countries located on the Mediterranean sea coast. A growing body of scientific literature pointed out the healthy effects of this diet. In recent years we investigated about the protective effects of a regular and moderate wine consumption. As we know, alcoholic and non alcoholic wine constituents are responsible of different effects by means of molecular and cell mechanisms. Among the non alcoholic components, polyphenols (for example resveratrol and quercetin) were deeply investigated. The aim of this review is to underline the effects of a moderate and regular wine drinking in the context of the Mediterranean diet in light of the interactions between wine and important dietary factors such as olive oil, fruit and vegetables.
\end{abstract}

Keywords: Wine; Alcohol; Polyphenols; Mediterranean Diet; Resveratrol; Cardiovascular Diseases; Cancer; Neurodegenerative Diseases

\section{Introduction}

The term "Mediterranean diet" is greatly employed to indicate the typical diet of the Countries located on the Mediterranean sea coast [1]. From ancient times, these populations were characterized by simple food habits as the high intake of whole cereals (pasta, bread, rice), fruits and vegetables (up to 400 grams/day in Greece), legumes and fish, olive oil as the common source of fats, poor intake of meat and dairy products and a moderate, regular wine drinking.

Several data underline the healthy effects of this diet [2].

In recent years we examined the protective effects of a regular and moderate wine consumption on diabetes mellitus [3], hypertension [4], endothelial function [5] and chronic renal failure [6].

The main goal of this review is to show the effects of a moderate and regular wine consumption in the context of a healthy diet such the Mediterranean one. For this reason, the complex influences exerted by wine on cardiovascular, metabolic and renal systems, neurodegenerative diseases and cancer must be mentioned.

\section{Wine and Cardiovascular Diseases}

The J-shaped alcohol-mortality curve is well known. Light drinkers have about $30 \%$ lower cardiovascular morbidity

\footnotetext{
${ }^{*}$ Corresponding author.
}

and mortality risk than abstainers, with about a $10 \%$ lower total mortality risk [7].

The positive effects arising from alcohol consumption could be reached only with 5 years of regular physical exercise [8]. Among the different alcoholic beverages, Gronbaek [9] demonstrated a reduced relative risk of mortality in subjects who daily consumed moderate amounts of wine; the same effect was not observed with beer and spirits.

In 1992 Renaud and De Lorgeril with the worldwide known "French paradox" [10] stigmatized such a relationship. This expression was coined to describe the relatively low incidence of cardiovascular disease observed in French population, in spite of a high dietary intake of saturated fats. Authors postulated that a regular wine consumption was responsible of the great difference they observed among France and other Northern European Countries in terms of cardiovascular mortality.

There are great amount of works in literature reporting the significant inverse relationship between wine drinking and cardiovascular mortality and morbidity $[11,12]$.

Nowadays, we know that wine exerts its protective effects by means of different mechanisms directed towards different targets. So to elucidate this effects we have to mention the influence of wine on lipoprotein metabolism, haemostasis and thrombosis and endothelial function.

As it is known, wine contains alcohol and non alcoholic components: among the latters, polyphenols play a leading role in determining wine effects. 


\subsection{Lipoprotein Metabolism}

Alcohol consumption leads to higher HDL-cholesterol levels, but the same effect was observed in animal models with alcohol-free red wine [13].

Red wine phenolic extract decrease plasma cholesterol, triglyceride and Apo B levels in hamsters [14]. In cell lines resveratrol inhibits lipid peroxidation and improves the efflux by which HDL removes the excess of cholesterol from macrophages. Such a process is fundamental for reverse cholesterol transport which, on its turn, is on the basis for protection against atherosclerosis [15].

Polyphenols inhibits LDL oxidation in a more powerful manner than vitamin $\mathrm{E}$ as demonstrated by Frankel [16]. Moreover red wine consumption reduces plasma levels of $\mathrm{Lp}(\mathrm{a})$ [17] that, as it is known, is able to reduce the fibrinolytic activity. Red wine constituents also inhibit foamcell synthesis [18].

Recently, in a double-blind, placebo-controlled trial post-infarction patients treated with resveratrol for three months showed a significant reduction of LDL cholesterol. [19]

\subsection{Haemostasis and Thrombosis}

An inverse relationship between alcohol consumption and both fibrinogen and antithrombin has been demonstrated [20]; other authors observed a direct association between alcohol consumption and protein S [18], ultimately stimulating the surface-localized endothelial cell fibrinolysis.

The same group showed is that differently from what observed with beer and spirits to which could be due ischaemic events 24 - 48 hours after consumption, wine does not exert rebound effects [9].

Three glasses a day of red wine can significantly inhibit platelet aggregation, more than what observed with grapejuice or resveratrol-enriched grape juice, thus underlining the role of alcoholic components [21]. Resveratrol, catechin and quercetin are powerful inhibitors of platelet aggregation by different mechanisms among which decreesed thromboxane synthesis with consequent reduced activation of cyclo- and lipo-oxygenase must be mentioned [22]. Many papers strengthened this particular action of wine thus leading to consider it an "aspirin-like" compound [23]. However, results in normal subjects are controversial and someone did not observed ex vivo the same response. This might depend on different factors such bioavailability, intestinal clearance or drinking amount [24].

\subsection{Endothelial Function}

Protection against cardiovascular diseases is exerted by wine polyphenols that play an important influence on endothelium. In animal models and cultured cells different authors showed a vasodilating effect elicited by wine [25]. On human endothelium wine's effects are rather contro- versial. In human umbilical vein endothelial cells (HUVEC) treated with a red wine polyphenolic extract Leikert [26] observed a significant nitric oxide (NO) increase via a raised eNOS protein expression. In the same cell line, resveratrol upregulated eNOS by stimulating promoter and transcription factors [27]. From these starting points, many studies on human volunteers proved a significant flowmediated dilation (FMD) after consuming a high fat meal associated with red wine [28,29]. After the observation of an increased FMD even with a dealcoholized red wine, some authors hypothesized the so called "Japanese Paradox" [30] with the creation of a tasty and healthy dealcoholized wine. Unfortunately, such investigations do not take account the important social role of the alcoholic beverages, expecially wine.

If we consider that polyphenols are detectable in the plasma of non supplemented humans at concentrations comparable to those required to induce $50 \%$ of maximal endothelium-dependent vasorelaxation, it can be hypothesized that in vivo effective concentrations can be reached [31].

In more than 300 men and 200 women who underwent coronary angiography, Liu et al. [32] showed that alcohol consumption was related to a lower risk of severe coronary stenosis in men, while in patients with angiographically documented coronary artery disease, Teragawa et al. [33] found that alcohol, if consumed at least once a week, positively influenced endothelial function.

Recently, Magyar showed that post infarction patients, treated with resveratrol show a significant improvement of endothelial function measured with FMD [19].

As we mentioned in our previous papers on this topic [3-6], all these data, rather controversial, lead us to think that beneficial effects could be due both to polyphenols and alcohol.

Many typical mediterranean foods, like onions, are a great source of polyphenols [34]. In fact, Mediterranean diet has been shown to reduce endothelial damage and to influence the endothelial ability to repair itself [35].

\subsection{Wine and Hypertension}

Hypertensives, according to WHO estimation [36], are about 600 millions and the number of prehypertensives is increasing. Hypertension is a common background in stroke [36] and a key factor in the progression of kidney disease [37]. A direct relationship between alcohol consumption and arterial hypertension is well documented [38] and this kind of association is also confirmed for a daily wine consumption greater than 3 glasses [39]. Some polyphenols, expecially quercetin (which is largely present in white wines) showed instead anti-hypertensive properties. In animal model of experimental hypertension, quercetin reduced blood pressure, cardiac and renal hypertrophy and blunted the hypertension-induced vascular 
remodeling in a dose-dependent manner [40]. In another model of salt-hypertensive rats, chronic oral administration of quercetin showed the same effects of verapamil on systolic blood pressure [41].

In the Predimed Study [42], a clinical, multicentric randomized, controlled trial total polyphenol urinary excretion, as biomarker of the total polyphenol intake, was measured in more than 500 subjects. This parameter was strictly inversely related to the prevalence of both systolic and diastolic hypertension. Polyphenols probably reduce arterial pressure also thanks to their ability to inhibit angiotensin converting enzyme, as demonstrated by ActisGoretta [43].

In light of all these considerations, it's easy to understand how the deep, complex interactions between dietary factors, wine and their pathophysiological targets could be responsible of a reduced cardiovascular risk.

\subsection{Wine and Renal Diseases}

The relationship between wine consumption and kidney disease is very interesting if we consider that chronic kidney disease is associated with accelerated atherosclerotic damage and more frequent cardiovascular events. Oxidative stress and endothelial dysfunction, which are interrelated [44], are involved in the pathophysiology of many renal diseases [45] In rat models of diabetic nephropathy, quercetin showed to be able in reducing the disease progression [46]. In human patients with the same chronic kidney disease a similar result was obtained with a polyphenol-enriched diet [47].

Another wine constituent, the phytoalexin resveratrol, showed inhibitory effects on proteinuria, hypoalbuminemia and hyperlipidemia in nephritic rats [48]. Its nephroprotective effects were usually ascribed to its ability in modulate nitric oxide production and endothelial function. In fact it enhances production and activity of endothelial nitric oxide synthase (eNOS) [27]. More recently Mannari and coworkers [49] hypothesized that nephroprotection could be also due to the sirtuin regulation by NO modulation. Sirtuins are a protein family which is involved in several different biological processes, from glucose homeostasis to aging and cancer. Sirtuin- 1 is the most investigated member of this family. It is a $\mathrm{NAD}(+)$ dependent deacetylase that regulates body stress responses by adjusting cell adaptations [50]. It is widely expressed in various tissues (liver, pancreas, muscles, adipose tissue, brain). Resveratrol activates sirtuin-1 via an allosteric interaction thus eliciting its effects.

\subsection{Wine and Diabetes Mellitus}

The association between wine consumption and diabetes mellitus has been largely examined. From the epidemiological point of view, Conigrave and coworkers [51] showed an inverse linear relationship between daily alcohol intake and diabetes; the corrected relative risk gave to white wine the major protective role. More recently, in the EPIC-InterAct Study [52] carried out in eight European Countries, a moderate alcohol consumption has been associated with a lower risk of developing diabetes in female population. The same result was not observed in males probably due to the different body fat distribution.

In animal models of metabolic syndrome (Zucker rats), Rivera [53] showed that a daily administration of resveratrol carried out for 4 weeks lead to a reduction of plasma glucose levels, triglycerides, total cholesterol, free fatty acids, insulin and leptin and a significant decrease of liver fat content. These effects were ascribed to the increased phosphorylation of AMP-activated protein kinase and acetyl-CoA carboxylase in the liver of these animals. Furthermore a significant improve in inflammatory conditions and an increased expression of eNOS in the visceral adipose tissue of the Zucker rats were noted.

In diabetic subjects, Ceriello and coworkers [54] some years ago showed as a standard meal is associated with a decrease of plasma total radical antioxidant power (TRAP); while if red wine is introduced in the same meal, the decrease of TRAP was not observed, thus underlining the antioxidant role of wine.

The antioxidant properties of wine polyphenols play a role in prevention of long term diabetic complications such as neuropathy, nephropathy and retinopathy. In fact polyphenols prevent the accumulation of oxidative/nitrative stress products in different body tissues as observed in animal models [55].

\subsection{Wine and Neurodegenerative Diseases}

It has been demonstrated, in various cell culture and animal models, that wine polyphenols protect neuronal cells by attenuating oxidative stress and cell damage. Regular wine consumption has been associated with a reduced incidence of neurodegenerative diseases. Among the polyphenols, resveratrol has been related with a lower reduction of Beta-amyloid via sirtuin-1 actions [50]. Resveratrol also acts on glial inflammation which is strictly involved in brain damage. In fact it has been demonstrated to be implicated in several cell mechanisms that lead to a reduced production of glial inflammatory mediators [56].

However, as suggested by Albarracin [57] and coworkers, it remains unclear how these compounds reach the brain, what concentrations are necessary, and what biologically active forms are needed to have beneficial effects. Therefore, further research is needed about this topic.

\subsection{Wine and Cancer}

The role of wine is controversial. A direct relationship 
between alcohol consumption and colo-rectal cancer has been reported and a similar association was observed for what regards liver, pharynx and larynx cancer [58-61]. A weaker association was observed between alcohol consumption and pancreas and neck cancer. No sure data are available for other many cancers whilst for what concerns the renal cancer a protective role of alcohol has been demonstrated [62].

Polyphenols, instead exert a protective role against cancer risk. Supposed mechanisms for this protections are: reduced expression of pro-oxidant enzymes which are involved in carcinogenesis; inhibition of transcription factor activation; apoptosis; impairment of cancer angiogenesis [63].

Recently resveratrol has been shown to involved in pain control, a crucial topic for cancer patients. In fact, it regulates nociceptive signaling via inhibition of cyclin-dependent kinase 5 (cdk5). Resveratrol blocks the TNF $\alpha$ mediated increase in p35 promoter activity thus reducing cdk5, which is actually considered a key target molecule for analgesia [64].

Besides wine, many dietary constituents were associated with cancer prevention: olive oil, fish, fruit and vegetables. Considering that all these foods are present in the Mediterranean diet, we have to look at this dietary habit as the healthiest one for prevention.

\section{Mediterranean Diet}

A great number of observational studies and clinical trials investigated about the relationship between dietary habits and cardiovascular disease, which is more interesting if we consider that the 169 billions of euro is how much cardiovascular diseases yearly cost.

One of the most important study in this field is the Seven Countries Study [65] in which a reduced consumption of saturated fatty acids is considered the leading cause of decreased cardiovascular mortality in Mediterranean Countries.

Such an observation was strongly confirmed by Renaud's so-called "Cretan Miracle” [66]. In fact, Cretan people, in spite of their high blood cholesterol levels, exhibited a low cardiovascular mortality due, on Renaud's opinion, to their healthy dietary habits, expecially for the high consumption of alfa-linolenic acid which is abundant in snails and walnuts.

Mediterranean diet is inversely related with body mass index, obesity and hypertension [67], even though its contribution in carbohydrate intake is high. This is reasonably due to many factors:

- The high consumption of fruit and vegetables; fruit consumption is inversely associated with cardiovascular and cerebrovascular risk both in men and women $[68,69]$.
- The significant intake of olive oil; it's the leading constituent of this diet. For its high polyphenols content, it has been demonstrated a powerful antiarrythmic, antiinflammatory, antioxidant and vasodilating compound, [70]. The favourable effects of olive oil have been ascribed to different mechanisms: reduction of LDLcholesterol levels and increase of HDL-cholesterol; lower susceptibility of LDLs to oxidation; improved endothelial function; better haemostasis and arterial pressure control. Olive oil also showed antineoplastic properties and ability to protect against neurodegenerative diseases [71].

- Regular consumption of garlic and onions. The former has shown to reduce blood pressure by means of angiotensin converting enzyme inhibiting activity. It also improves endothelial function by stimulating nitric oxide production and scavenging free radicals. Onions have fibrinolytic and hypotensive effects probably due to the high content of quercetin that is widely known to reduce blood pressure in hypertensives. The effects of onions' consumption are strengthened by the presence in the same meal of olive oil and red wine.

- Fish consumption. It has been associated with a reduction of cardiovascular risk. Regular fish intake has been inversely related with ischemic stroke. A similar relationship is not applicable to hemorrhagic stroke because omega-3 have a potential antiaggregant activity [72]. Protective effects of fish have been extended to cancer, aging and Alzheimer's disease [73] It supplies excellent amount of proteins, low saturated fats, long-chain and omega-3 polyunsaturated fatty acids (PUFA). This topic gained a great attention after the observations regarding the myocardial preconditioning [74]. At this regard, diet and healthy lifestyle (that is, for example, a regular physical activity [75]) are actually considered the most powerful preconditioners to reduce the ischemic myocardial damage. Among dietary factors, a diet with an increased omega-3 PUFA intake and a poor consumption of saturated fatty acids and omega-6 PUFA showed the best results in myocardial protection against ischemic injury [76]. The Mediterranean diet typically has a fatty acids profile very similar to the ideal one. Moreover, the lack in this diet of great amounts of omega-6 PUFA is more interesting if we consider that these fatty acids showed strong effects in enhancing breast cancer [77].

\section{Conclusions}

A regular and moderate wine consumption, associated with a simple, healthy diet such the Mediterranean one, is an advisable life habit. Beyond theoretical hypotheses, polyphenols could find clinical applications and in fact resveratrol tablets are already available as antiviral. 
More recently, resveratrol and quercetin have been employed in developing drug-eluting polymer coatings for endovascular devices. The gradual release of therapeutical concentration of these agents is useful to avoid the in-stent stenosis [78].

In light of all these considerations, a regular and moderate wine consumption, (The so called "Mediterranean way of drinking" of Giocosa and coworkers [79]) accompanied by Mediterranean-style diet and physical activity could be considered a wise prescription for healthy and ill people. At this regard, to seal its fundamental role in preventive strategies, Mediterranean diet obtained in 2010 the acknowledgment of UNESCO as an Intangible Cultural Heritage of Humanity.

\section{REFERENCES}

[1] R. M. Ortega, "Importance of Functional Foods in the Mediterranean Diet,” Public Health Nutrition, Vol. 9, No. 8A, 2006, pp. 1136-1140. doi:10.1017/S1368980007668530

[2] A. Menotti, A. Alberti-Fidanza, F. Fidanza, M. Lanti and D. Fruttini, "Factor Analysis in the Identification of Dietary Patterns and Their Predictive Role in Morbid and Fatal Events," Public Health Nutrition, Vol. 15, No. 7, 2012, pp. 1232-1239.

[3] G. Caimi, C. Carollo and R. Lo Presti, "Diabetes Mellitus: Oxidative Stress and Wine," Current Medical Research and Opinion, Vol. 19, No. 7, 2003, pp. 581-86. doi:10.1185/030079903125002324

[4] G. Caimi, C. Carollo and R. Lo Presti, "Wine, Diet and Arterial Hypertension,” Angiology, Vol. 58 No. 1, 2007, pp. 92-96. doi: $10.1177 / 0003319706295478$

[5] G. Caimi, C. Carollo and R. Lo Presti, "Chronic Renal Failure: Oxidative Stress, Endothelial Dysfunction and Wine," Clinical Nephrology, Vol. 62, No. 5, 2004, pp. 331-335.

[6] G. Caimi, C. Carollo and R. Lo Presti, "Wine Consumption and Renal Diseases: New Perspectives,” Nutrition, Vol. 23, No. 7, 2007, pp. 598-602. doi:10.1016/j.nut.2007.04.012

[7] A. L. Klatsky, G. D. Friedman, M. A. Armstrong and H. Kipp, "Wine, Liquor, Beer and Mortality," American Journal of Epidemiology, Vol. 158, No. 6, 2003, pp. 585595. doi:10.1093/aje/kwg184

[8] A. L. Klatsky, G. D. Friedman and A. B. Siegelaub, “Alcohol Consumption before Myocardial Infarction. Results from the Kaiser-Permanente Epidemiologic Study of Myocardial Infarction,” Annals of Internal Medicine, Vol. 81, No. 3, 1974, pp. 294-301.

[9] M. Gronbaek and T. I. Sorensen, "Alcohol Consumption and Risk of Coronary Heart Disease,” British Medical Journal, Vol. 313, No. 7053, 1996, pp. 365-366. doi:10.1136/bmj.313.7053.365

[10] S. Renaud and M. De Lorgeril, "Wine, Alcohol, Platelets and the French Paradox for Coronary Artery Disease,” Lancet, Vol. 339, No. 8808, 1992, pp. 1523-1526.

\section{doi:10.1016/0140-6736(92)91277-F}

[11] R. Estruch and R. M. Lamuela-Raventòs, "Alcohol, Wine and Cardiovascular Disease, Two Sides of the Same Coin,” Internal and Emergency Medicine, Vol. 5, No. 4, 2010, pp. 277-279. doi:10.1007/s11739-010-0391-8

[12] A. Di Castelnuovo, S. Costanzo, M. B. Donati, L. Iacoviello and G. De Gaetano, "Prevention of Cardiovascular Risk by Moderate Alcohol Consumption: Epidemiologic Evidence and Plausible Mechanisms," Internal and Emergency Medicine, Vol. 5, No. 4, 2010, pp. 291-297. doi:10.1007/s11739-010-0346-0

[13] J. Araya, R. Rodrigo, M. Orellana and G. Rivera, "Red Wine Raises Plasma HDL and Preserves Long-Chain Polyunsaturated Fatty Acids in Rat Kidneys and Erythrocytes," British Journal of Nutrition, Vol. 86, No. 2, 2001, pp. 189-195. doi:10.1079/BJN2001369

[14] C. Auger, B. Caporiccio, N. Landrault, P. L. Teissedre, C. Laurent and G. Cros, "Red Wine Phenolic Compounds Reduce Plasma Lipids and Apolipoprotein B and Prevent Early Aortic Atherosclerosis in Hypercholesterolemic GoIden Syrian Hamsters (Mesocricetus auratus)," Journal of Nutrition, Vol. 132, No. 6, 2002, pp. 1207-1213.

[15] H. Berrougui, G. Grenier, S. Loued, G. Drouin and A. Khalil, "A New Insight into Resveratrol as an Atheroprotective Compound: Inhibition of Lipid Peroxidation and Enhancement of Cholesterol Efflux," Atherosclerosis, Vol. 207, No. 2, 2009, pp. 420-427. doi:10.1016/j.atherosclerosis.2009.05.017

[16] E. N. Frankel, J. Kanner, J. B. German, E. Parks and J. E. Kinsella, "Inhibition of Oxidation of Human Low-Density Lipoproteins by Phenolic Substances in Red Wine," Lancet, Vol. 20, No. 341, 1993, pp. 454-457.

[17] E. B. Rimm, P. Williams, K. Fosher, M. Criqui and M. J. Stampfer, "Moderate Alcohol Intake and Lower Risk of Coronary Heart Disease. Meta-Analysis of Effects on Lipids and Haemostatic Factors,” British Medical Journal, Vol. 319, No. 7224, 1999, pp. 1523-1528. doi:10.1136/bmj.319.7224.1523

[18] G. Lippi, M. Franchini, E. J. Favaloro and G. Targher, "Moderate Red Wine Consumption and Cardiovascular Disease Risk: Beyond the French Paradox," Seminars in Thrombosis and Hemostasis, Vol. 36, No. 1, 2010, pp. 59-70. doi:10.1055/s-0030-1248725

[19] K. Magyar, R. Halmosi, A. Palfi, G. Feher, L. Czopf and A. Fulop, "Cardioprotection by Resveratrol: A Human Clinical Trial in Patients with Stable Coronary Artery Disease," Clinical Hemorheology and Microcirculation, Vol. 50, No. 3, 2012, pp. 179-187.

[20] D. Mezzano, F. Leighton, C. Martínez, G. Marshall, A. Cuevas and O. Castillo, "Complementary Effects of Mediterranean Diet and Moderate Red Wine Intake on Haemostatic Cardiovascular Risk Factors,” European Journal of Clinical Nutrition, Vol. 55, No. 6, 2001, pp. 444-451. doi:10.1038/sj.ejcn.1601202

[21] D. M. Goldberg, V. Garovic-Kocic, E. P. Diamandis and C. R. Pace-Asciak, "Wine: Does the Colour Count?" Clinica Chimica Acta, Vol. 15, No. 246, 1996, pp. 183-193. doi:10.1016/0009-8981(96)06229-8

[22] C. R. Pace-Asciak, O. Rounova, S. E. Hahn, E. P. Dia- 
mandis and D. M. Goldberg, "Wines and Grape Juices as Modulators of Platelet Aggregation in Healthy Human Subjects," Clinica Chimica Acta, Vol. 246, No. 1-2, 1996, pp. 163-182. doi:10.1016/0009-8981(96)06236-5

[23] V. L. Serebruany and D. R. Lowry, "Take an Aspirin or Have a Drink: Antecedent Aspirin and Moderate Alcohol Consumption Similarly Affect Baseline Platelet Characteristics in Patients with Acute Myocardial Infarction,” Journal of Thrombosis and Haemostasis, Vol. 84, No. 11, 2000, pp. 933-934.

[24] M. G. Tozzi Ciancarelli, C. Di Massimo, D. De Amicis, I. Ciancarelli and A. Carolei, "Moderate Consumption of Red Wine and Human Platelet Responsiveness," Thrombosis Research, Vol. 128, No. 124, 2011, pp. 124-129.

[25] D. Taubert, R. Berkels, W. Klaus and R. Roesen, "Nitric Oxide Formation and Corresponding Relaxation of Porcine Coronary Arteries Induced by Plant Phenols: Essentials Structural Features,” Journal of Cardiovascular Pharmacology, Vol. 40, No. 701, 2002, pp. 701-713. doi:10.1097/00005344-200211000-00008

[26] J. F. Leikert, T. R. Rathel, P. Wohlfart, V. Cheynier, A. M. Vollmar and V. M. Dirsch, "Red Wine Polyphenols Enhance Endothelial Nitric Oxide Synthase Expression and Subsequent Nitric Oxide Release from Endothelial Cells," Circulation, Vol. 106, No. 13, 2002, pp. 16141617. doi:10.1161/01.CIR.0000034445.31543.43

[27] T. Wallerath, G. Deckert, T. Ternes, H Anderson, H. Li and K. Witte, "Resveratrol, a Polyphenolic Phytoalexin Present in Red Wine, Enhances Expression and Activity of Endothelial Nitric Oxide Synthase," Circulation, Vol. 106, No. 13, 2002, pp. 1652-1658. doi:10.1161/01.CIR.0000029925.18593.5C

[28] S. Agewall, S. Wright, R. N. Doughty, G. A. Whalley, M. Duxbury and N. Sharpe, "Does a Glass of Red Wine Improve Endothelial Function?” European Heart Journal, Vol. 21, No. 1, 2000, pp. 74-78. doi:10.1053/euhj.1999.1759

[29] L. Djoussè, R. C. Ellison, C. E. McLennan, L. A. Cupples, I. Lipinska and G. H. Tofler, "Acute Effects of a High-Fat Meal with and without Red Wine on Endothelial Function in Healthy Subjects," American Journal of Cardiology, Vol. 84, No. 6, 1999, pp. 660-664. doi:10.1016/S0002-9149(99)00412-9

[30] T. O. Cheng, "Is Dealcoholized Red Wine the Final Solution? The Japanese Paradox," American Journal of Cardiology, Vol. 89, No. 9, 2002, p. 1150. doi:10.1016/S0002-9149(02)02263-4

[31] G. Paganga and C. A. Rice-Evans, "The Identification of Flavonoids as Glycosides in Human Plasma," FEBS Letters, Vol. 401, No. 1, 1997, pp. 78-82. doi:10.1016/S0014-5793(96)01442-1

[32] Y. Liu, H. Tanaka, S. Sasazuki, K. Yoshimasu, H. Kodama and M. Washio, "Alcohol Consumption and Severity of Angiographically Determined Coronary Artery Disease in Japanese Men and Women," Atherosclerosis, Vol. 156, No. 1, 2011, pp. 177-183. doi:10.1016/S0021-9150(00)00627-4

[33] H. Teragawa, Y. Fukuda, K. Matsuda, Y. Higashi, T. Yamagata and H. Matsuura, "Effect of Alcohol Consump- tion on Endothelial Function in Men with Coronary Artery Disease," Atherosclerosis, Vol. 165, 2002, pp. 145-152. doi:10.1016/S0021-9150(02)00193-4

[34] J. H. M. De Vries, P. C. H. Hollman, I. Van Amersfoort, M. R. Olthof and M. B. Katan, "Red Wine Is a Poor Source of Bioavailable Flavonols in Men,” Journal of Nutrition, Vol. 131, 2001, pp. 745-758.

[35] C. Marin, R. Ramirez, J. Delgado-Lista, E. M. YuberoSerrano, P. Perez-Martinez and J. Carracedo, "Mediterranean Diet Reduces Endothelial Damage and Improves the Regenerative Capacity of Endothelium," The American Journal of Clinical Nutrition, Vol. 93, No. 2, 2011, pp. 267-274. doi:10.3945/ajcn.110.006866

[36] G. Mancia, "Prevention and Treatment of Stroke in Patients with Hypertension," Clinical Therapeutics, Vol. 26, No. 5, 2004, pp. 631-648. doi:10.1016/S0149-2918(04)90065-3

[37] G. Maschio, L. Oldrizzi, C. Marcantoni and C. Rugiu, "Hypertension and Progression of Renal Failure," Journal of Nephrology, Vol. 13, 2000, pp. 225-227.

[38] G. Corrao, V. Bagnardi, A. Zambon and C. La Vecchia, "A Meta-Analysis of Alcohol Consumption and the Risk of 15 Diseases," Preventive Medicine, Vol. 38, No. 5, 2004, pp. 613-619. doi:10.1016/j.ypmed.2003.11.027

[39] D. B. Panagiotakos, C. H. Pitsavos, C. Chrysohoou, J. Skoumas, L. Papadimitriou and C. Stefanadis, "Status and Management of Hypertension in Greece: Role of Adoption of a Mediterranean Diet: The ATTICA Study," Journal of Hypertension, Vol. 21, No. 8, 2003, pp. 1483-1489. doi:10.1097/00004872-200308000-00011

[40] J. Duarte, R. Perez-Palencia, F. Vargas, M. A. Ocete, F. Perez-Vizcaino and A. Zarzuelo, "Antihypertensive Effects of the Flavonoid Quercetin in Spontaneously Hypertensive Rats," British Journal of Pharmacology, Vol. 133, No. 1, 2001, pp. 117-124. doi:10.1038/sj.bjp.0704064

[41] M. Galisteo, M. F. Garcìa-Saura, R. Jimènez, I. C. Villar, A. Zarzuelo and F. Vargas, "Effects of Chronic Quercetin Treatment on Antioxidant Defence System and Oxidative Status of Deoxycorticosterone Acetate-Salt-Hypertensive Rats," Molecular and Cellular Biochemistry, Vol. 259, No. 1-2, 2004, pp. 91-99. doi:10.1023/B:MCBI.0000021360.89867.64

[42] A. Medina-Remón, R. Zamora-Ros, M. Rotchés-Ribalta, C. Andres-Lacueva, M. A. Martínez-González and M. I. Covas, "Total Polyphenol Excretion and Blood Pressure in Subjects at High Cardiovascular Risk," Nutrition, Metabolism \& Cardiovascular Diseases, Vol. 21, No. 5, 2011, pp. 323-331. doi:10.1016/j.numecd.2009.10.019

[43] L. Actis-Goretta, J. I. Ottaviani and C. G. Fraga, "Inhibition of Angiotensin Converting Enzyme Activity by Flavanol-Rich Foods," Journal of Agricultural and Food Chemistry, Vol. 54, No. 1, 2006, pp. 229-234. doi:10.1021/jf0522630

[44] M. Annuk, M. Zilmer and B. Fellstrom, "EndotheliumDependent Vasodilation and Oxidative Stress in Chronic Renal Failure: Impact on Cardiovascular Disease,” Kidney International, Vol. 63, No. 84, 2003, pp. S50-S53. doi:10.1046/j.1523-1755.63.s84.2.x 
[45] R. Rodrigo and G. Rivera, "Renal Damage Mediated by Oxidative Stress. A Hypothesis of Protective Effects of Red Wine,” Free Radical Biology and Medicine, Vol. 33, No. 3, 2002, pp. 409-422. doi:10.1016/S0891-5849(02)00908-5

[46] M. Anjaneyulu and K. Chopra, "Quercetin, an Antioxidant Bioflavonoid, Attenuates Diabetic Nephropathy in Rats," Clinical and Experimental Pharmacology and Physiology, Vol. 31, No. 4, 2004, pp. 244-248. doi:10.1111/j.1440-1681.2004.03982.x

[47] F. S. Facchini and K. L. A. Saylor, "Low-Iron Available, Polyphenol-Enriched, Carbohydrate-Restricted Diet to Slow Progression of Diabetic Nephropathy,” Diabetes, Vol. 52, No. 5, 2003, pp. 1204-1209. doi:10.2337/diabetes.52.5.1204

[48] T. Nihei, Y. Miura and K. Yagasaki, "Inhibitory Effect of Resveratrol on Proteinuria, Hypoalbuminemia and Hyperlipidemia in Nephritic Rats," Life Sciences, Vol. 68, No. 25, 2001, pp. 2845-2852. doi:10.1016/S0024-3205(01)01061-X

[49] C. Mannari, A. A. Bertelli, G. Stiaccini and L. Giovannini, "Wine, Sirtuins and Nephroprotection: Not Only Resveratrol,” Medical Hypotheses, Vol. 75, No. 6, 2010, pp. 636-638. doi:10.1016/j.mehy.2010.08.004

[50] V. Guarani and M. Potente, "SIRT1-A Metabolic Sensor that Controls Blood Vessel Growth," Current Opinion in Pharmacology, Vol. 10, No. 2, 2010, pp. 139-145. doi:10.1016/j.coph.2010.01.001

[51] K. M. Conigrave and E. B. Rimm, "Alcohol for the Prevention of Type 2 Diabetes Mellitus?” Treatments in Endocrinology, Vol. 2, No. 3, 2003 pp. 145-152. doi:10.2165/00024677-200302030-00001

[52] J. W. Beulens, Y. T. Van der Schouw, M. M. Bergmann, S. Rohrmann, M. B. Schulze and B. Bujisse, "Alcohol Consumption and Risk of Type 2 Diabetes in European Men and Women: Influence of Beverage Type and Body Size. The EPIC-Inter Act Study," Journal of Internal Medicine, Vol. 272, No. 4, 2012, pp. 358-370.

[53] L. Rivera, R. Moròn, A. Zarzuelo and M. Galisteo, "LongTerm Resveratrol Administration Reduces Metabolic Disturbances and Lowers Blood Pressure in Obese Zucker Rats,” Biochemical Pharmacology, Vol. 77, No. 6, 2009, pp. 1053-1063. doi:10.1016/j.bcp.2008.11.027

[54] A. Ceriello, N. Bortolotti, E. Motz, N. Lizzio, B. Catone and R Assaloni, "Red Wine Protects Diabetetics from Meal-Induced Oxidative Stress and Thrombosis Activation: A Pleasant Approach to the Prevention of Cardiovascular Diseases in Diabetes," European Journal of Clinical Investigation, Vol. 31, No. 4, 2001, pp. 322-328. doi:10.1046/j.1365-2362.2001.00818.x

[55] V. R. Drel and N. Sybirna, "Protective Effects of Polyphenolics in Red Wine on Diabetes Associated Oxidative/ Nitrative stress in Streptozotocin-Diabetics Rats," Cell Biology International, Vol. 34, No. 12, 2010, pp. 11471153. doi:10.1042/CBI20100201

[56] F. Zhang, F. J. Liu and J. S. Shi, “Anti-Inflammatory Activities of Resveratrol in the Brain: Role of Resveratrol in Microglial Activation,” European Journal of Pharmacology, Vol. 636, No. 1-3, 2010, pp. 1-7. doi:10.1016/j.ejphar.2010.03.043

[57] S. L. Albarracin, B. Stab, Z. Casas, J. J. Sutachan, I. Samudio and J. Gonzalez, "Effects of Natural Antioxidants in Neurodegenerative Diseases," Nutritional Neuroscience, Vol. 15, No. 1, 2012, pp.1-9.

[58] T. Mizoue, K. Tanaka, I. Tsuji, K. Wakai, C. Nagataand and T. Otani, "Alcohol Drinking and Colo-Rectal Cancer Risk: An Evaluation Based on a Systematic Review of Epidemiologic Evidence among the Japanese Population,” Japanese Journal of Clinical Oncology, Vol. 36, No. 9, 2006, pp. 582-597. doi:10.1093/jjco/hyl069

[59] K. Tanaka, I. Tsuji, K. Wakai, C. Nagata, T. Mizoue and M. Inoue, “Alcohol Drinking and Liver Cancer Risk: An Evaluation Based on a Systematic Review of Epidemiologic Evidence among the Japanese Population,” Japanese Journal of Clinical Oncology, Vol. 38, No. 12, 2008, pp. 816-838.

[60] E. T. Chang, and H. O. Adami, "The Enigmatic Epidemiology of Naso-Pharyngeal Carcinoma," Cancer Epidemiology, Biomarkers \& Prevention, Vol. 15, No. 10, 2006, pp. 1765-1777. doi:10.1158/1055-9965.EPI-06-0353

[61] M. P. Purdue, M. Hashibe, J. Berthiller, C. La Vecchia, L. Dal Maso and R. Herrero, “Type of Alcoholic Beverage and Risk of Head and Neck Cancer-A Pooled Analysis within the Inhance Consortium," American Journal of Epidemiology, Vol. 169, No. 2, 2008, pp. 132-142. doi:10.1093/aje/kwn306

[62] J. E. Lee, D. J. Hunter, D. Spiegelman, H. O. Adami, D. Albanes and L. Bernstein, "Alcohol Intake and Renal Cell Cancer in a Pooled Analysis of 12 Prospective Studies," Journal of the National Cancer Institute, Vol. 99, No. 10, 2007, pp. 801-810. doi:10.1093/jnci/djk181

[63] T. Sharif, C. Auger, M. Alhosin, C. Ebel, M. Achour and N. Eienne-Selloum, "Red Wine Polyphenols Cause Growth Inhibition and Apoptosis in Acute Lymphoblastic Leukaemia Cells by Inducing a Redoxsensitive Up-Regulation of p73 and Down-Regulation of UHRF1,” European Journal of Cancer, Vol. 46, No. 5, 2010, pp. 983-994. doi:10.1016/j.ejca.2009.12.029

[64] E. Utreras, A. Terse, J. Keller, M. J. Iadarola and A. B. Kulkarni, "Resveratrol Inhibits cdk5 Activity through Regulation of p35 Expression,” Molecular Pain, Vol. 7, 2011, pp. 49-63. doi:10.1186/1744-8069-7-49

[65] A. Keys, "Diet and Coronary Heart Disease," Lancet, Vol. 264, No. 6827, 1954, pp. 37-38. doi:10.1016/S0140-6736(54)90023-9

[66] B. Simini and S. Renaud, "From French Paradox to Cretan Miracle,” Lancet, Vol. 355, No. 9197, 2000, p. 48. doi:10.1016/S0140-6736(05)71990-5

[67] C. Lazarou, D. Panagiotakos and A. L. Matalas, "The Role of Diet in Prevention and Management of Type 2 Diabetes: Implications for Public Health," Critical Reviews in Food Science and Nutrition, Vol. 52, No. 5, 2012, pp. 382-389. doi:10.1080/10408398.2010.500258

[68] L. Dauchet, P. Amouyel and J. Dallongeville, "Fruit, Vegetables and Coronary Heart Disease,” Nature Reviews 
Cardiology, Vol. 6, No. 9, 2009, pp. 599-608. doi:10.1038/nrcardio.2009.131

[69] J. F. He, C. A. Nowson and G. A. MacGregor, "Fruit and Vegetable Consumption and Stroke: Meta-Analysis of Cohort Studies,” Lancet, Vol. 367, No. 9507, 2006, pp. 320-326. doi:10.1016/S0140-6736(06)68069-0

[70] J. López-Miranda, F. Pérez-Jiménez, E. Ros, R. De Caterina, L. Badimón and M. I. Covas, "Olive Oil and Health: Summary of the II International Conference on Olive Oil and Health Consensus Report, Jaén and Córdoba (Spain) 2008," Nutrition, Metabolism \& Cardiovascular Diseases, Vol. 20, No. 4, 2010, pp. 284-294. doi:10.1016/j.numecd.2009.12.007

[71] M. I. Covas, "Bioactive Effects of Olive Oil Phenolic Compounds in Humans: Reduction of Heart Disease Factors and Oxidative Damage," Inflammapharmacol, Vol. 16, No. 5, 2008, pp. 216-218. doi:10.1007/s10787-008-8019-6

[72] V. Demarin, M. Lisak and S. Morovic, "Mediterranean Diet in Healthy Lifestyle and Prevention of Stroke," Acta Clinica Croatica, Vol. 50, No. 1, 2011, pp. 67-77.

[73] V. Solfrizzi, V. Frisardi, D. Seripa, G. Logroscino, B. P. Imbimbo and G. D’Onofrio, "Mediterranean Diet in Predementia and Dementia Syndromes," Current Alzheimer Research, Vol. 8, No. 5, 2011, pp. 520-542. doi:10.2174/156720511796391809

[74] C. E. Murry, R. B. Jennings and K. A. Reimer, "New
Insights into Potential Mechanisms of Ischemic Preconditioning,” Circulation, Vol. 84, 1991, pp. 442-445.

[75] J. W. Starnes and R. P. Taylor, "Exercise-Induced Cardioprotection: Endogenous Mechanisms,” Medicine \& Science in Sports \& Exercise, Vol. 39, 2007, pp. 15371543. doi:10.1249/mss.0b013e3180d099d4

[76] G. G. Abdukeyum, A. J. Owen and P. L. McLennan, "Dietary (n-3) Long-Chain Polyunsaturated Fatty Acids Inhibit Ischemia and Reperfusion Arrhythmia and Infarction in Rat Heart not Enhanced by Ischemic Preconditioning," Journal of Nutrition, Vol. 138, 2008, pp. 747752.

[77] L. M. Braden and K. K. Carroll, "Dietary Polyunsaturated Fat in Relation to Mammary Carcinogenesis in Rats," Lipids, Vol. 21, No. 4, 1986, pp. 285-288. doi:10.1007/BF02536414

[78] J. J. Kleinedler, J. D. Foley, J. S. Alexander, S. C. Roerig, V. Y. Hebert and T. R. Dugas, "Synergistic Effect of Resveratrol and Quercetin Released from Drug-Eluting Polymer Coatings for Endovascular Devices," Journal of Biomedical Materials Research Part B: Applied Biomaterials, Vol. 99, No. 2, 2011, pp. 266-275. doi:10.1002/jbm.b.31894

[79] A. Giocosa, R. Barale, L. Bavaresco, P. Gatenby, V. Gerbi and J. Janssens, "Cancer Prevention in Europe: The Mediterranean Diet as a Protective Choice," European Journal of Cancer Prevention, Vol. 22, No. 1, 2012, pp. 90-95. 